\title{
Macugonalia Young (Hemiptera, Cicadellidae, Cicadellinae): duas novas espécies de Minas Gerais, Brasil ${ }^{1}$
}

\author{
Rodney Ramiro Cavichioli ${ }^{2}$ \\ ${ }^{1}$ Contribuição número 1452 do Departamento de Zoologia, Universidade Federal do Paraná. \\ ${ }^{2}$ Departamento de Zoologia, Universidade Federal do Paraná. Caixa Postal 19020, 81531-980 Curitiba, Paraná, Brasil. \\ Bolsista do CNPq. E-mail: cavich@ufpr.br
}

\begin{abstract}
Macugonalia Young (Hemiptera, Auchenorrhyncha, Cicadellidae): two news species from Minas Gerais, Brazil. Two new species of Macugonalia Young, 1977 from Itamonte, Minas Gerais, Brazil, are described. The two new species present the same pattern male genitalia of others species of the genus: aedeagus short, convex dorsally with a pair of elongate slender processes arising basiventrally, but with others pattern of coloration, sternite VII and shape of the adeagus different of the others species.

KEY WORDS. Cicadellini, description, new species, taxonomy.
\end{abstract}

RESUMO. Duas novas espécies de Macugonalia Young, 1977 são descritas, de Itamonte, Minas Gerais, Brasil. As duas novas espécies apresentam o mesmo padrão da genitália dos machos das demais espécies do gênero: edeago curto, convexo dorsalmente e com um par de longos processos, delgados, originando-se na região basiventral. Porém, as duas espécies apresentam outros padrões de colorações, esternito VII e forma do edeago diferentes das demais espécies do gênero.

PALAVRAS CHAVE. Cicadellini, descrição, novas espécies, taxonomia.

Macugonalia foi descrito por Young (1977), designando como espécie-tipo Tettigonia sobrina Stål, 1862 e incluiu oito espécies novas no gênero, além de propor dezoito novas combinações e duas sinonímias.

Analisando-se espécimes coletados em Itamonte, Minas Gerais, depositados na coleção de entomologia do Museu Nacional, Universidade Federal do Rio de Janeiro [MNRJ], propõe-se duas novas espécies: Macugonalia elegantula sp. nov. e Macugonalia nefasta sp. nov.

A terminologia utilizada para os caracteres da morfologia é aquela de Young $(1968,1977)$, exceto para cabeça, onde se segue Hamilton (1981) e MejDalani (1998), para as estruturas da genitália das fêmeas, utiliza-se Nielson (1965). A metodologia para o estudo das genitálias dos machos e das fêmeas seguiu as técnicas descritas por OMAN (1949) e ZANOL (1988). As medidas são fornecidas em milímetros.

\section{Macugonalia elegantula sp. nov. Figs 1-10}

Holótipo macho: Brasil. Minas Gerais: Itamonte, 16-20/ X/1997, Fêlix, Mejdalani \& Takiya leg. (MNRJ). Alótipo fêmea: Mesmo dados do Holótipo (MNRJ). Parátipos: 2 machos e 6 fêmeas, mesmos dados do holótipo; um macho e uma fêmea depositados na coleção de entomologia "Pe. Jesus Santiago
Moure" do Departamento de Zoologia da Universidade Federal do Paraná (DZUP), demais no Museu Nacional do Rio de Janeiro (MNRJ).

Medidas (holótipo/alótipo). Comprimento total: 8,07/ 8,46; comprimento mediano da cabeça:0,56/0,60; distância transocular:2,20/2,40; distância interocular: 1,44/1,52; comprimento mediano do pronoto: 1,16/1,16; distância entre os úmeros: 2,00/2,08.

Holótipo macho. Cabeça, em vista dorsal, não produzida, com comprimento aproximadamente $1 / 5$ e 3/10 da distância transocular e quase $2 / 5$ da interocular; margem anterior arredondada, sem carena na transição entre a coroa e a face; ocelos salientes, localizados atrás da linha imaginária que tangencia os bordos anteriores dos olhos e, mais próximos destes do que da linha mediana da coroa; superfície da coroa lisa; lóbulos supra-antenais, em vista dorsal, não protuberantes e, em vista lateral, oblíquos e não carenados. Fronte, em vista frontal, levemente achatada medianamente, de perfil, intumescida e levemente arqueada, com impressões musculares evidentes; sutura fronto-clipeal inteira. Clípeo, em vista lateral, contínuo com a fronte, com uma leve angulação no terço apical. Pronoto mais estreito do que a cabeça, com comprimento mediano aproximadamente $6 / 10$ da distância entre os úmeros; margens anteriores convergentes anteriormente; margem posterior mais ou menos reta; superfície do disco do pronoto lisa; 

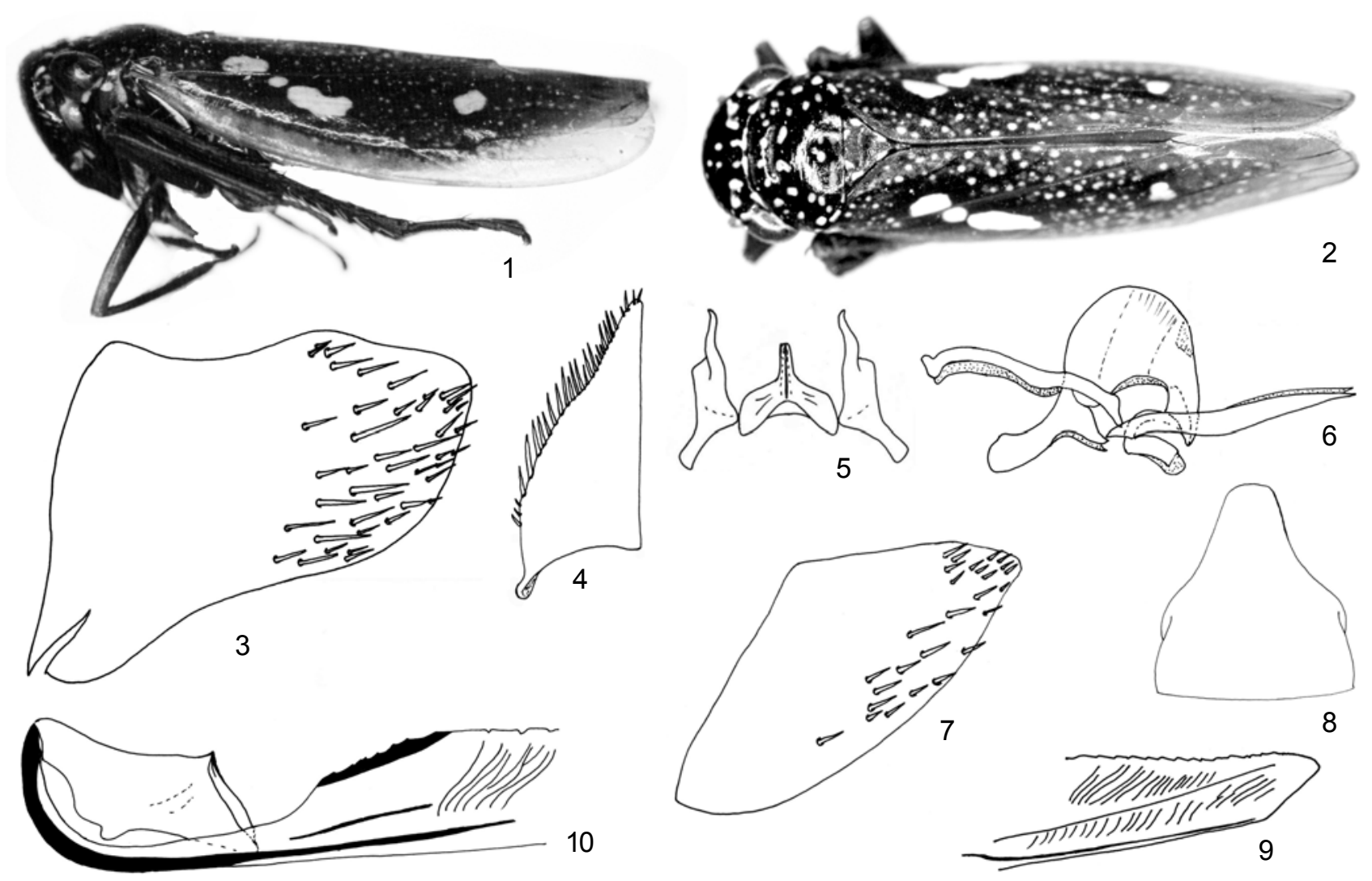

Figuras 1-10. Macugonalia elegantula sp. nov.: (1) vista lateral; (2) vista dorsal; (3) pigóforo do macho, em vista lateral; (4) placa subgenital, vista ventral; (5) estilos e conetivo, vista dorsal; (6) edeago, em vista lateral; (7) pigóforo da fêmea, em vista lateral; (8) esternito VII, vista ventral; (9) base da Segunda valva e segundo valvífero, em vista lateral; (10) ápice da segunda valva, em vista lateral.

carena dorso-pleural completa. Escutelo mais largo basalmente do que longo, sem estrias e com um sulco no terço apical. Asas anteriores com comprimento quase quatro vezes sua largura mediana; com três células anteapicais fechadas, com as bases menos proximais do que o ápice do clavo; com quatro células apicais, a base da terceira mais proximal do que da quarta; venação distinta, sem veias extranumerárias ou plexo de veias. Pernas posteriores com fórmula setal femural 2.1.1; tarsômeros basais com comprimento maior que a soma dos dois mais distais e com duas fileiras de pequenas cerdas na superfície plantar. Pigóforo mais longo do que sua maior largura, com macrocerdas distribuídas no terço apical e margem apical levemente angulada. Placa subgenital triangular, bipartida, comprimento igual a 2/3 do comprimento do pigóforo e com duas fileiras de macrocerdas nas margens laterais. Estilos mais longos do que conetivo; apicalmente afilados e com lóbulo pré-apical. Conetivo em " $Y$ ", em vista dorsal, carenado medianamente. Edeago curto, achatado lateralmente, apicalmente com um processo agudo voltado para baixo, com um par de processos basi-ven- trais longos, delgados e agudos apicalmente.

Fêmea. Semelhante ao macho. Pigóforo longo, com a margem apical aguda. Esternito VII triangular, de comprimento igual a metade do comprimento do pigóforo. Segunda valva com a porção basal da área denteada fortemente esclerotinizada, dentes uniformes; segundo valvífero mais ou menos retangular.

Coloração. No aspecto geral, castanha. Cabeça, pronoto e escutelo de coloração preta, com várias pequenas máculas amarelas esparsas. Asas anteriores castanhas, com muitas manchas amarelas pequenas e arredondadas, com três manchas maiores amarelas, formando uma linha oblíqua no terço basal, sendo uma no clavo e outras duas no cório, podendo apresentar outra, pouco menor e de forma arredondada no terço apical, próxima ao ápice do clavo. Região das três manchas amarelas maiores, em geral, castanho-escura.

Comentários. Macugonalia elegantula sp. nov. é similar, no aspecto geral, ao grupo formado por M. geographica (Signoret, 1855), M. dallasi (Signoret, 1853), M. spinolai (Signoret, 1853) e M. semiguttata (Signoret, 1853), onde todas apresentam man-

Revista Brasileira de Zoologia 21 (1): 123-126, março 2004 


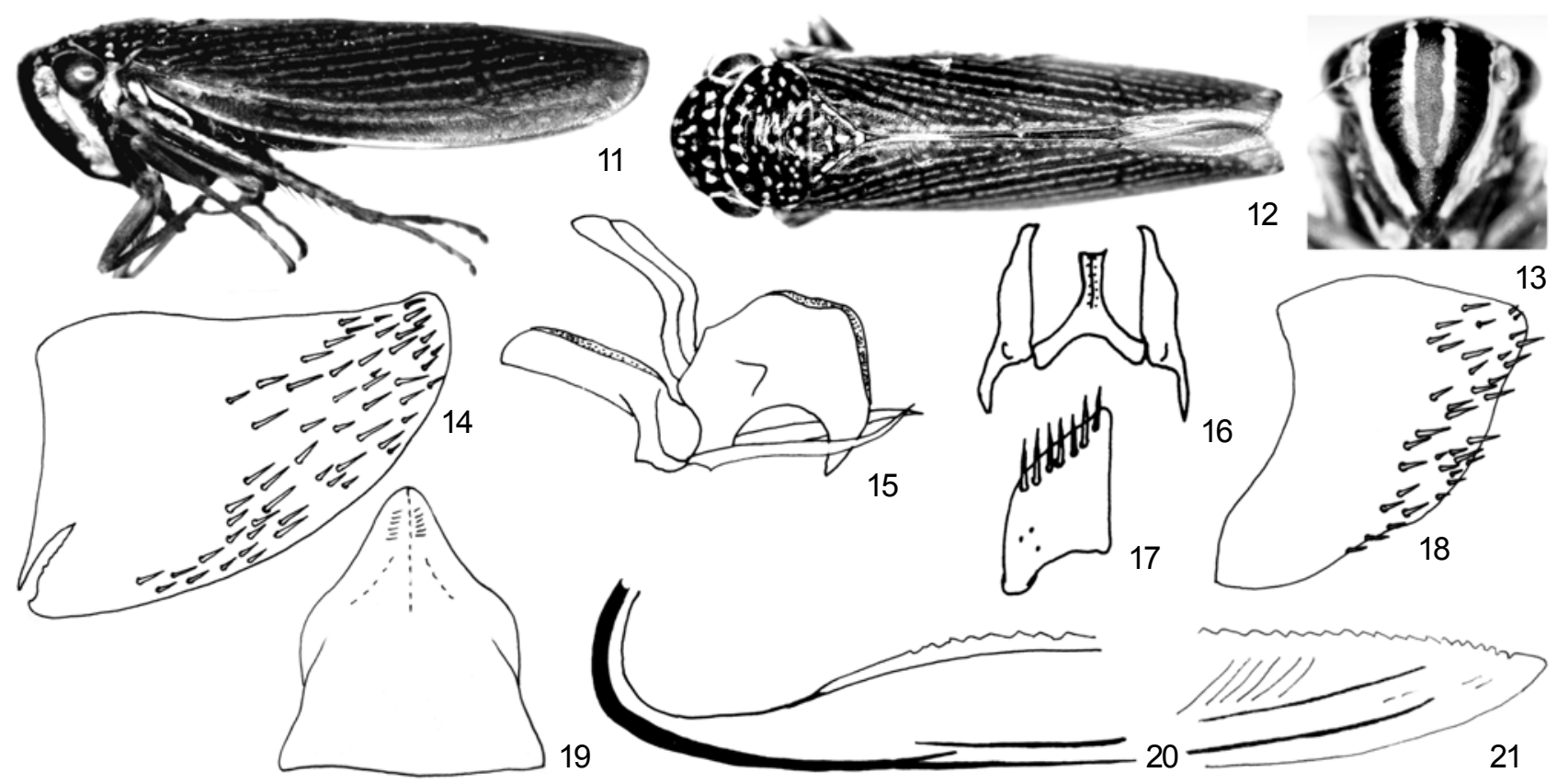

Figuras 11-21. Macugonalia nefasta sp. nov.: (11) vista lateral; (12) vista dorsal; (13) cabeça em vista frontal; (14) pigóforo do macho, em vista lateral; (15) edeago, em vista lateral; (16) estilos e conetivo, vista dorsal; (17) placa subgenital, vista ventral; (18) pigóforo da fêmea, em vista lateral; (19) esternito VII, vista ventral; (20) base da Segunda valva, em vista lateral; (21) ápice da segunda valva, em vista lateral.

chas amarelas na base das asas anteriores. Porém, a nova espécie difere dessas, pelo tamanho, coloração geral e estrutura da genitália do macho, principalmente, quanto à placa subgenital que é relativamente longa em M. elegantula sp. nov.

\section{Macugonalia nefasta sp. nov.}

Figs 11-21

Holótipo macho, BrasiL, Minas Gerais: Itamonte, 16-20/ X/1997, Fêlix, Mejdalani \& Takiya leg. (MNRJ). Alótipo fêmea: Mesmo dados do Holótipo (MNRJ). Parátipos: 10 machos e 6 fêmeas, um macho e uma fêmea depositados na coleção de entomologia "Pe. Jesus Santiago Moure" do Departamento de Zoologia da Universidade Federal do Paraná (DZUP), demais no Museu Nacional do Rio de Janeiro (MNRJ).

Medidas (holótipo/alótipo). Comprimento total:6,60/ 6,80; comprimento mediano da cabeça:0,52/0,60; distância transocular: 1,80/2,04; distância interocular: 1,12/1,36; comprimento mediano do pronoto: 0,86/1,08; distância entre os úmeros: $1,60 / 1,88$.

Holótipo macho. Cabeça, em vista dorsal, não pronunciada, com comprimento mediano aproximadamente $3 / 10$ da distância transocular e quase $2 / 5$ da distância interocular. Demais características semelhantes às de Macugonalia elegantula sp. nov. Pronoto mais estreito do que a cabeça, comprimento me- diano levemente maior do $1 / 2$ da distância entre os úmeros. Outros caracteres semelhantes aos da espécie anteriormente descrita. Pigóforo longo, com a margem apical obtusa e dobrada internamente, formando curtos processos; macrocerdas distribuídas desde no terço apical e margem ventral. Placa subgenital curta, triangular, bipartida, com macrocerdas no terço apical. Estilos mais longos do que o conetivo e afilados apicalmente. Conetivo em " $\mathrm{Y}$ ", em vista dorsal, carenado medianamente. Edeago achatado lateralmente, curvado para baixo e com ápice agudo, com um par de processos basi-ventrais, delgados e agudos apicalmente.

Fêmea. Semelhante ao macho. Pigóforo triangular, mais largo basalmente do que longo. Esternito VII triangular, com uma leve carena médio-apical. Segunda valva com dentes triangulares.

Coloração. No aspecto geral, castanho-avermelhada. Cabeça, pronoto e escutelo de coloração preta, com várias pequenas manchas amarelo-claras; face com três faixas longitudinais estreitas e pretas. Asas anteriores castanho-avermelhas, com pequenas pontuações amarelo-claras ao longo das veias e a região da primeira célula apical despigmentada.

Comentários. Macugonalia nefasta sp. nov. é similar a $M$. tribunicia (Berg, 1879) e M. pyrrhoptera (Stål, 1862), sendo que estas duas apresentam um padrão semelhante de coloração, segundo Young (1977), que, ao analisar o lectótipo de Tettigonia 
pyrrhoptera Stål, 1862 e comparando com M. tribunicia, salientou que T. pyrrhoptera apresenta as faixas longitudinais da fronte mais estreitas do que em $M$. tribunicia e a ausência das pequenas máculas ao longo das veias das asas anteriores. Macugonalia nefasta sp. nov. apresenta as faixas estreitas na fronte e pigmentação amareladas ao longo das veias.

\section{AGRADECIMENTOS}

Agradeço ao Conselho Nacional de Desenvolvimento Científico e Tecnológico (CNPq) pela Bolsa de Produtividade em Pesquisa e pelo auxílio concedido referente ao processo $n^{\circ}$ 475565/01-0.

\section{REFERÊNCIAS BIBLIOGRÁFICAS}

Hamilton, K.G.A. 1981. Morphology and evolution of the rhynchotan head (Insecta: Hemiptera, Homoptera). Canadian Entomologist, Ottawa, 113: 953-974.

Mejdalani, G. 1998. Morfologia externa dos Cicadellinae (Homoptera, Cicadellidae): comparação entre Versigonalia ruficauda (Walker) (Cicadellini) e Tretogonia cribrata
Melichar (Proconiini), com notas sobre outras espécies e análise da terminologia. Revista Brasileira de Zoologia, Curitiba, 15 (2): 451-544.

Nielson, M.W. 1965. A revision of the genus Cuerna (Homoptera, Cicadellidae). Technical Bulletin of the United States Department of Agriculture, Washington, D.C., 1318: 1-48.

Oman, P.W. (1949). The Nearctic leafhoppers (Homoptera: Cicadellidae). A generic classification and check list. Memoirs of the Entomological Society of Washington, Washington, D.C., 3: 1-253.

Young, D.A. 1968. Taxonomic study of the Cicadellinae (Homoptera: Cicadellidae). Part 1, Proconiini. Bulletin of the United States National Museum, Washington, D.C., 261: 1-287.

. 1977. Taxonomic study of the Cicadellinae (Homoptera: Cicadellidae). Part 2, New World Cicadellini and the genus Cicadella. Bulletin of the North Carolina Agricultural Experiment Station, North Carolina, 239: 1-1135.

Zanol, K.M.R. 1988. Morfologia de Neophlepsius gracilis (Osborn, 1923) (Homptera, Cicadellidae, Deltocephalinae). Revista Brasileira de Entomologia, São Paulo, 32 (1): 69-93.

Recebido em 11.VII.2003; aceito em 24.II.2004.

Revista Brasileira de Zoologia 21 (1): 123-126, março 2004 